\title{
REVIEW
}

\section{Are errors in otorhinolaryngology always a sign of medical malpractice? Review of the literature and new perspectives in the SARS-CoV-2 (COVID-19) era}

\author{
Gli errori medici in otorinolaringoiatria sono sempre indici di colpa medica? Revisione \\ della letteratura e nuove prospettive nell'era SARS-CoV-2 (COVID-19) \\ Polychronis Voultsos ${ }^{*}$, Antonio Oliva2, Simone Grassi², Debora Palmiero², Antonio Gioacchino Spagnolo² \\ 1 Department of Medical Ethics, Aristotle University of Thessaloniki, Thessaloniki, Greece; ${ }^{2}$ Department of Healthcare Surveillance \\ and Bioethics, Catholic University of the Sacred Heart, Rome, Italy \\ P. Voultsos and A. Oliva contributed equally to this work.
}

\begin{abstract}
SUMMARY
In medical practice, during certain procedures that usually are not regarded highly demanding, some skill-based errors, that might not be considered as medical malpractice, may occur. In fact, such errors can be caused by factors beyond the physician's control.A review of Greek case law regarding medical malpractice in otorhinolaryngology was performed to identify cases of lawsuits that concerned medical errors during routine procedures. The analysis of the cases showed that some medical errors may cause serious complications, even if deviation from the standard of medical care is minimal. Thus, in some cases it may be difficult to make a distinction between preventable and unpreventable complications. Certain medical errors from routine medical procedures might be considered unpreventable and, therefore, classified as almost no-fault errors. A brief commentary regarding opportunities to further improve the medical liability system after the SARS-CoV-2 emergency is also given.
\end{abstract}

KEY WORDS: medical error, medical malpractice, negligence, otorhinolaryngology, COVID-19

\section{RIASSUNTO}

In ambito medico legale, durante alcune procedure non particolarmente complesse, possono verificarsi errori che potrebbero non essere necessariamente ricondotti a colpa medica. La ragione è che tali errori possono essere causati da fattori che vanno oltre il controllo del medico. È stata fatta una revisione della legislazione greca, riguardante casi di colpa medica in otorinolaringoiatria, allo scopo di identificare i casi giuridici riguardanti errori medici durante tali procedure. L'analisi dei casi ha evidenziato che alcuni errori medici possono causare complicanze serie, anche in caso di errori minimi che deviano di poco dallo standard di trattamento. Per questo motivo, in alcuni casi può essere difficile distinguere tra complicanze prevedibili e non prevedibili. Alcuni errori, che si verificano durante procedure mediche di routine, potrebbero essere considerati non prevedibili e per questo classificati come errori "quasi" senza colpa. Viene infine fornito un breve commento sulle opportunità di migliorare ulteriormente il sistema di responsabilità medica dopo l'emergenza SARS-CoV-2.

PAROLE CHIAVE: errore medico, colpa medica, negligenza, otorinolaringoiatria, COVID-19

\section{Introduction}

In Ear-Nose-Throat (ENT) surgery, errors can be committed even by a skillful surgeon. However, otorhinolaryngology is a medical specialty with a low rate of malpractice. In a recent study of the American College of Surgeons, it
Received: February 7, 2020

Accepted: May 5, 2020

Published online: June 10, 2020

\section{Correspondence}

Antonio Oliva

Department of Healthcare Surveillance and Bioethics, Catholic University of the Sacred Heart, largo Francesco Vito 1, 00168 Rome, Italy Tel. +3906 30154249, +390630157033

E-mail: antonio.oliva@unicatt.it

\section{Funding}

This work has been supported by Linea D1 Fondi di Ateneo Università Cattolica del Sacro Cuore to Antonio Oliva.

Conflict of interest

The Authors declare no conflict of interest.

\begin{abstract}
How to cite this article: Voultsos P, Oliva A, Grassi S, et al. Are errors in otorhinolaryngology always a sign of medical malpractice? Review of the literature and new perspectives in the SARS-CoV-2 (COVID-19) era. Acta Otorhinolaryngol Ital 2020;40:157-163. https://doi org/10.14639/0392-100X-N0674
\end{abstract}

(c) Società Italiana di Otorinolaringoiatria e Chirurgia Cervico-Facciale

\section{cc) (i) $(9)$}

This is an open access article distributed in accordance with the CC-BY-NC-ND (Creative Commons Attribution-NonCommercial-NoDerivatives 4.0 International) license. The article can be used by giving appropriate credit and mentioning the license, but only for non-commercial purposes and only in the original version. For further information: https:// creativecommons.org/licenses/by-nc-nd/4.0/deed.en 
was found that only $12 \%$ of otolaryngologists had received claims against them in the past two years ${ }^{1}$, while a Danish study found an increasing trend in the number of otorhinolaryngology malpractice claims.

In this specialty, complications are seldom severe, but are strongly surgery-related ${ }^{2}$, and, therefore, proper technical and non-technical skills and full compliance with guidelines and international standards are pivotal to avoid malpractice litigation ${ }^{3}$. "ENT Today" reported in October 2013 that, during the period 2007-2011, 53\% of allegations against otolaryngologists were associated with "improper performance of surgery". Among 40 claims lodged in the UK for malpractice related to tonsillectomy (TE) during the period 1995-2010, the most common injury was postoperative bleeding, followed by nasopharyngeal regurgitation (a potential injury of the glossopharyngeal nerve that may occur during ENT surgery) ${ }^{4}$. A German study, which included the 50 most common inpatient ENT surgical procedures (septoplasty, TE with or without adenoidectomy (AE), etc.), detected "surgical malpractice" in $6.1 \%$ of all cases ${ }^{5}$. The complexity of ENT surgery, along with individual anatomical variations and the close proximity to critical anatomical structures, may explain why some severe complications should be considered inevitable, even for the most skilled - and experienced surgeon, especially in the case of transnasal surgery and functional endoscopic sinus surgery (FESS) ${ }^{6}$. In these cases, such errors may be classified as "almost system errors" and considered as unpreventable adverse events. In this paper, we discuss three Greek cases of errors in Otorhinolaryngology, showing the main technical and medico-legal issues. Our aim is to underline that not all technical errors should be always considered as medical malpractice.

\section{Case descriptions}

A review of the Greek legal database was performed over the period of the past 15 years. Three cases of medical malpractice, due to erroneous maneuvers of ENT surgeon, were identified (summarised in Tab. I). More specifically, two concerned erroneous surgical maneuvers resulting in injury to anatomical structures. One case concerned medical maneuvers (which caused laryngeal injury and, hence, a fatal reflex reaction) performed in the post-operative phase and under emergency conditions.

\section{Case 1}

Judgment No. 1135/1993 of the Greek Supreme Court ("Areios Pagos") regards the case of an otolaryngologist who was trying to stop a heavy nasal bleeding that occurred during a septoplasty. Therefore, he was putting pressure using forceps directly on a piece of gauze, which he had inserted into the nasal cavity, against the bleeding area. He applied too much pressure on the forceps, causing its shift towards the upper part of the nasal cavity, breaking the cribriform plate of the ethmoid bone. This resulted in a hole through which the endocranial and nasal cavities communicated. Thus, a large volume of air entered the endocranial cavity, causing swelling of nasal mucosa and the right sinus, resulting in radiological finding of an hyperdense mass at the right caudate nucleus of the endocranial cavity, communicating hydrocephalus of the lobe, meningoencephalitis and inflammation of the brain ventricles due to antibiotic-resistant staphylococcus and Candida fungus. The otolaryngologist who performed the operation abandoned the patient without informing the director. Diagnosis of the complication was done by CT performed six days after surgery. The surgeon was aware of what had happened, and hence, he should have informed the other physicians treating the patient. The Court sentenced him to a term of 18-months detention.

\section{Case 2}

Judgment No. 3127/2009 of the Three-Member Court of Appeal of Thessaloniki concerned an excessive tissue resection during a TE under local anesthesia that resulted in impaired function of the glossopharyngeal nerve (with subsequent rhinolalia aperta, reduced mobility and sensory disturbances to the soft palate and facial arches). The injury of the glossopharyngeal nerve was established through an expert report two years after the surgery. The surgeon was found guilty.

\section{Case 3}

In Judgment No. 4639/2002 of the Three-Member Court of

Table I. Case summaries.

\begin{tabular}{|c|c|c|c|}
\hline Cases & Procedure & Claimed error & Conviction \\
\hline 1 & Septoplasty & Rupture of the cribriform plate of the ethmoid bone & 18-months detention \\
\hline 2 & Tonsillectomy & $\begin{array}{c}\text { Excessive tissue resection resulting in impairment of the glossopharyngeal } \\
\text { nerve function }\end{array}$ & Guilty (unknown) \\
\hline 3 & Abrupt insertion of the suction device & $\begin{array}{l}\text { Fatal injury of the laryngeal aperture (stimulation of the vagus nerve and } \\
\text { cardiac arrest) }\end{array}$ & 1-year detention \\
\hline
\end{tabular}


Appeal of Athens, a physician on duty was sentenced to a term of 1-year detention for having inserted, in an "abrupt and unskillful manner", the metal nozzle of the tube of a suction device used to remove excretions that had accumulated postoperatively in the airways of a 16-year-old female patient who underwent surgery for turbinate hypertrophy and removal of a small nasal spine. Insertion of the nozzle may cause complications such as injuries and uncontrolled stimulation of the vagus nerve that may lead to cardiac arrest and death, which is the case in question. Post-mortem examination revealed injuries to the laryngeal aperture, confirming their iatrogenic nature.

\section{Discussion}

Regarding case 1, septoplasty is one of the most common operations in ENT surgery ${ }^{7}$ and cerebrospinal fluid (CSF) leak is one of its possible complications ${ }^{7}$. When it occurs after septoplasty, it is mainly attributed to a cribriform plate defect inadvertently caused by a physician during the surgical procedure (iatrogenic complication) ${ }^{7,8}$. Fractures of the cribriform plate are related to poor technique or inadvertence, such as in the following cases: poor angling of dissection forceps, elevation of forceps beyond the ethmoid roof ${ }^{9}$ and forceful removal of the perpendicular plate ${ }^{10}$ of the ethmoid (by applying a multidirectional force). "Slitshaped dehiscence at the horizontal lamella of the cribriform plate" may also be observed ${ }^{10}$. Surgeons should consider the occurrence of an undiagnosed encephalocele ${ }^{11}$ or meningoencephalocele formation after septoplasty ${ }^{12}$.

In Judgment No. 1135/1993 of the Supreme Court, the surgeon's inadvertence resulted in perforation of the cribriform plate in attempting to control bleeding that occurred during septoplasty. In our opinion, this case is exemplary because the serious complication might be viewed as being "in all likelihood unavoidable", provided that the subjective perception of the surgeon (who was under stress) played an essential role. To avoid the occurrence of a CSF fistula, multidirectional forces should not be applied and accurate preoperational knowledge of the possible anatomical variations would be essential ${ }^{13}$. Importantly, the ethmoid roof level may be different on each side (right and left) ${ }^{14}$. Bony structures in the anterior cranial fossa are very thin and dura mater is tightly attached to them ${ }^{7}$. In the case of a CSF fistula, the symptoms appear immediately after septoplasty. CSF leakage typically occurs after 12-22 weeks ${ }^{10}$. Notwithstanding, Soni et al. reported a case of CSF leakage that occurred 2 weeks after septoplasty ${ }^{11}$. During septoplasty (especially endoscopic septoplasty), a surgeon may use some anatomical landmarks in order to reduce the probability of complications. Interestingly, Seth et al. stated that "the inferior turbinate and vertical middle turbinate attachment may be used to guide the extent of cartilage resection" ${ }^{15}$. Some of these landmarks may not be totally reliable. Schultz-Coulon recommend the use of a microscope to obtain optimal visualisation and sparing of the junction area between the lamina quadrangularis and perpendicularis. It is not clear whether under those particular circumstances it would be possible even for a very skillful, experienced and diligent surgeon to be aware of the borderline between due and excessive pressure exerted on the cribriform plate of the ethmoid bone. In addition, it is worth mentioning that the cribriform plate is so thin that it can be broken during the intra-operative phase without the surgeon noticing it.

Regarding case 2, nerve lesions may occur during ENT surgery due to errors in surgical procedures, resulting in deterioration of the patient's quality of life. In TE with or without adenoidectomy (AE), injuries of the shaft or tonsillar or lingual branches of the ninth cranial nerve may develop, resulting in dysgeusia and ageusia as well as motor disorders of the soft palate, resulting in rhinolalia aperta, regurgitation, or a combination of both ${ }^{16}$. Velopharyngeal insufficiency following TE is reported in the literature, and, hence, preoperative evaluation of the anatomical variations in the velopharynx is recommended ${ }^{16}$. A very rare but distressing type of lesion to the ninth cranial nerve due to TE is the underdiagnosed secondary glossopharyngeal neuralgia. When the dissection starts in the incorrect surgical plane during TE, injury of the ninth nerve may possibly occur because of the proximity of the nerve's course to the tonsillar fossa ${ }^{16}$. Not only there is a close proximity between the cranial nerves and the area where TE is performed, but there are also different motor and sensory pathways in the same nerves ${ }^{16}$. Therefore, the same medical error may result in complications that could be classified into different severity. Lesions of the superficial petrol nerve endings may occur during TE. Lesion to the hypoglossal nerve occurs less frequently during TE in comparison with lesion of the glossopharyngeal nerve because of the deep anatomical position of the nerve. A lesion to the hypoglossal nerve can hardly ever occur without serious concurrent bleeding, given the proximity of the nerve to carotid artery branches. During TE, an injury of the aberrant courses of the internal carotid artery may occur.

As in this specific case, "excessive tissue resection" may occur in TE, resulting in nerve injuries. However, there may be cases where it may be (almost) impossible for a very skillful, experienced and diligent surgeon to distinguish the due tissue resection from the excessive one. It is known that in the area of the pharynx, inside the same nerves, there are different sensory and motor pathways and it is difficult 
to make accurate detection of the anatomical course of a nerve, especially of its branches and endings. Therefore, it is necessary having a great awareness of which nerves are at risk. It is also to be noted that aberrant vessels may run close to the oropharynx, rhinopharynx and the tonsil fossa. Thus, some nerve injuries in ENT surgery might be classified as 'in all likelihood unpreventable'.

In case 3, the Court of Appeal of Athens concluded that the defendant conduct was neither as diligent nor as accurate as it should have been. In fact, the physician inserted abruptly the nozzle of the suction device tube. The negligence was considered gross since the breach of duty consisted in a clear and significant deviation from the standard of care and occurred in a phase of the procedure in which no particular technical or non-technical skills were required to achieve a good outcome (the consequences of error would have been likely avoidable if the required attention had been paid).

\section{General medico-legal concerns}

Negligence usually includes doing something that an ordinary, reasonable and prudent practitioner would not do, or not doing something that a person like that would do considering circumstances and knowledge. In case that the "objective bystander" reconstruct (ex post) the micromovements of a particular surgical procedure, some of them might be found to be erroneous, while they are not, in all likelihood, foreseeable from the perspective (ex ante) of an ordinary physician of the relative specialty, because of their high complexity. A physician who committed an erroneous maneuver should be regarded as he made a "mistake of fact", by reducing or eliminating the physician's civil liability or criminal culpability, only in the case in which an ordinary, reasonable, and prudent physician, working under similar circumstances, could not adapt micro-maneuvers to the conditions of the particular patient. There are cases of erroneous medical maneuvers, occurring during routine procedures, in which a sharp line of distinction between medical negligence and no-fault error may be extremely difficult to be drawn. It is difficult to rule out with certainty that a given erroneous medical maneuver was practically unavoidable and hence constitutes a "no-fault error". The preventability of an erroneous maneuver may be established with the probability, according to which a maneuver might be classified as (almost) negligence (in case of high degree of preventability) or (almost) no-fault error (in case of low degree of preventability).

In cases 1 and 3, the adverse event may be viewed as "in all likelihood unpreventable", whereas in case 2 it may be considered "in average likelihood" unpreventable. The line drawn between unwitting no-fault error and inadvertent negligence-based error may be blurry. This may be due to a variety of factors such as: fallibilities and risks inherent in excellence of a medical specialty, fallibilities inherent in the physician's mind and environmental factors that may influence the physician, as well as the interaction among these factors. Subjective perception plays a leading role, for example, when the physician should have performed a "careful penetration of an instrument" or should have exerted a "mild" pressure on a delicate and brittle anatomic structure to stop the bleeding. A surgeon may be involved in medical litigation for an unavoidable complication due to "unpredictable" situations (e.g. those due to the "idiosyncrasy", the particularities of the patient, or spontaneous movement of the patient's body during a surgical procedure). Additionally, a physician may find himself acting under the influence of situational factors (e.g. conditions of extreme stress). Regarding the case of a physician who exerts a certain pressure on an anatomical structure, the focus should be put on the physician's awareness of that pressure. We may assume that, when pressure has been exerted on a thin bone surface, the degree of awareness may be determined by analogous situations experienced before. Moreover, such influences may result from dynamic and complex interactions between factors such as the physician's biorhythm, stress, distress and other (mostly environmental) factors. These factors may deprive a physician of abilities not only to perfectly reflect and ponder, but also to be fully aware of what he/she is doing.

Certain routine medical error cases should not be considered medical malpractice because of their complexity and difficulty. In order to classify them as "too much complex and difficult", every single event of the medical procedure should be strictly analysed, as well as the circumstances under which the procedure was carried out. The adverse events that result from erroneous medical maneuvers considered "in all likelihood unpreventable" should be classified as almost no-fault errors. Sohn remarks that negligence is not at the centre of most medical errors ${ }^{17}$, thus implying that most of them are, in reality, system errors.

\section{The no-fault compensation system}

The no-fault compensation system seems to better serve the purposes of civil medical liability, which is focused on the patient (namely, on restoration of damage) rather than the physician (namely, on indictment and sentence or payment of compensation). Sohn stated that probably "a more rational system would focus more on the goals of compensation and improvement, rather than on punishment for those who err" ${ }^{17}$. Notwithstanding, medical negligence is considered a failure to meet a requisite standard of care ${ }^{17}$. This 
is probably the main reason why French Jurisprudence of the courts oscillated between two positions: the obligation of the physician to guarantee a safe result by correctly carrying out a surgical procedure, and the obligation to satisfy the standard of care, which correspond to the rules of "good medical practice" and prudence ${ }^{18}$. In Italy, medical tort and criminal law were radically reformed by Law N. 24/2017. This law can be considered a "safe harbour law": when a physician commits an error and the error causes injury and avoidable harm to the patient, he cannot be considered criminally liable if full compliance with national guidelines or international/national best practices (e.g. international guidelines) is proven. Obviously, this "safe harbour" cannot be granted in cases of gross negligence (when the conduct significantly deviated from the standard of care). Regarding tort law, when the defendant committed the error in a public or private hospital, the plaintiff (the patient) must prove breach of duty (while, before the Law N. 24/2017, in many cases the defendant had to prove his innocence). This rule is not valid in cases of lawsuits directly against hospitals: when this occurs, the hospital has to prove that the claim is unfounded. This shift of the burden of proof is substantial, because it aims to deflate the lawsuits against physicians but, at the same time, allows patients to obtain compensation directly from hospitals ${ }^{19}$.

It is important to mention a current and critical problem worldwide, namely severe acute respiratory syndrome coronavirus 2 (SARS-Cov-2). This outbreak began with a cluster of cases of pneumonia in Wuhan (December 31, 2019) and increasingly spread globally, with the World Health Organization declaring a pandemic (March 11, 2020). During this critical period, the Italian Government introduced Decree-Law N. 18 (March 17, 2020) in order to reduce the impact of Covid-19 and strengthen Public Health through its reorganisation. In fact, in the most highly affected regions of the country, many hospitals (both public and private) have been turned into Covid-centers ${ }^{20}$. However, Decree-Law N. 18 provides nothing about medical liability, and therefore an amendment has been recently proposed. This concerns the abolition of both civil and criminal liability for medical errors, occurring in this critical time, except in cases of serious professional misconduct and willful misconduct. Moreover, according to this proposal, cases of serious professional misconduct would be assessed by taking into account the number of patients in need of care and availability of medical resources (health professionals, medical devices) considering the emergency situation in which the medical staff is working. However, this amendment is currently under consideration, and has not been approved.

In general terms, since unpreventable (or in all likelihood unpreventable) technical medical errors resulting from routine medical procedures should not be regarded as medical negligence, the implementation of the "no-fault" system would be considered as a necessary reform of the medical malpractice system. Importantly, the particularities of each single case should be examined carefully and precisely in order to establish if the given case of medical error would be eligible for compensation through the so-called "nofault compensation system" or not. The so-called "system errors" would be more fairly addressed through the "nofault" compensation system. Generally speaking, system errors are errors for which the responsibility is institutional rather than individual. Sohn states that system error is an "occasional", "simple", "unwitting", "unavoidable" human error ${ }^{17}$. A system error is attributable to the healthcare system or bureaucracy, such as organisational error (staffing, failure to have expert mentorship, etc.) or improper processes (drug carts set out improperly, etc.). A kind of system error might be physicians having to be on call for significant periods of time without enough rest. Importantly, the line of distinction between system error and individual error may be blurry when it comes to technical human errors resulting from difficult, complicated and complex surgical procedures such as those examined before. It is argued in the literature that the "no-fault" system has more benefits compared to the negligence-based model, by reducing the costs of litigation and improving patient care ${ }^{(21)}$. Moreover, the "no-fault" system serves the interests of all the stakeholders involved in medical malpractice: patient, physician, healthcare system and the whole community. It is further argued that there is a strong public interest in the implementation of the "no-fault system" ${ }^{17}$. Not surprisingly, the "no-fault" system seems to be better applied when it comes to injuries caused during ultra high-risk surgical procedures, in which surgeon negligence is difficult to ascertain ${ }^{22}$. This may happen even if the surgeon is experienced, skillful and prudent ${ }^{23}$.

As emerged from the documents retrieved from the proceedings of the trials, the overriding and ultimate goal of all the claimants was not economic, namely, they wanted to achieve the punishment of physicians who erred. Some claimants wanted to find out what really happened. Thus, in case of a medical error that might be viewed as almost "nofault" error, the claimants' goal may not be, most likely, the punishment of the physician. As a consequence, many claimants might seek noneconomic types of redress. In addition, the amount of the compensation sought might be lower and there might not be criminal cases against physicians. Interestingly, according to the "no-fault system" the extent of compensation is generally lower than that concerning the tort system, and therefore with budgets similar 
to the costs of the tort system more patients would be compensated. Finally, it is crucial to bear in mind that, contrary to the negligence-based system that "objectifies" medical liability and according to the "no-fault system", physicians might be unpunished, and hence would be strongly discouraged from practicing "defensive medicine" ${ }^{17}$, which represents a huge cost for Public Health ${ }^{24}$. The "no-fault system" benefits both physicians and patients, and fosters a good relationship between them ${ }^{21}$. In this perspective, the patient's trust in the doctor would be strengthened, leading to an improvement in the quality of healthcare. Moreover, it also promotes the public interest by reducing the huge costs of litigation and those of "defensive medicine" 21,25,26. These two aspects especially concern surgeons compared to clinicians, since they have a higher risk of medico-legal events ${ }^{27}$ since they are involved in surgical procedures which, in most cases, are at high risk of errors due to their complexity and difficulty. Moreover, in support of the nofault compensation system, the 1982 President's Commission for the Study of Ethical Problems in Medicine and Biomedical Behavioral Research stated that "a successful compensation system would treat like cases alike, make fair payment for the harm sought to be remedied, and disburse funds with maximum efficiency and minimum administrative cost" 28 .

\section{Conclusions}

There are routine medical procedures in which erroneous medical maneuvers may cause serious complications even though the deviation from the standard of medical duty of care (or diligence/prudence) was only slight. Under certain circumstances, it may be extremely difficult to draw a sharp line of distinction between avoidable and unavoidable complications caused by such maneuvers. Additionally, under particular circumstances, it may be very difficult or impossible to make "ex post" effective and reliable judgment about a physician's negligence. Skill-based medical failures may be caused by situational factors that can strongly influence the physician's control over his/her abilities. In conclusion, there are technical medical errors resulting from routine medical procedures that are unavoidable or in all likelihood unavoidable. These errors might be classified as almost no-fault errors. The adoption of the "no-fault compensation system" by the medical liability system seems to address the aforementioned errors in a fair manner. In Greece, the implementation of the no-fault system should be supported within a narrow range inclusive of "in all likelihood unpreventable" human errors resulting from routine medical procedures. Compensation of such errors through the no-fault system would offer significant advantages (e.g. compensation in a timely manner, disclosure of the errors). Of note, however, the "no-fault" system's alleged disadvantages would in all likelihood remain unobserved, provided that the tort system will keep compensating the majority of medical errors. Our ambition is to offer an instrument to make better judgments about medical liability. However, more work is needed to increase awareness of this topic, especially after the SARS-CoV-2 emergency. During this critical period, the Italian Government introduced DecreeLaw N. 18 (March 17, 2020) in order to reduce the impact of Covid-19 and strengthen Public Health through its reorganisation. This document also concerns the proposal regarding the abolition of both civil and criminal liability for medical errors, occurring in this critical time, except those cases of serious professional misconduct and willful misconduct. Although this amendment is currently under consideration and is not still approved, it represents a good opportunity to further improve the medical liability system in Italy as well.

\section{References}

1 Balch CM, Oreskovich MR, Dyrbye LN et al. Personal consequences of malpractice lawsuits on American surgeons. J Am Coll Surg 2011;213:657-67. https://doi.org/10.1016/j.jamcollsurg.2011.08.005

2 Coelho DH, Tampio AJ. The Utility of the MAUDE database for osseointegrated auditory implants. Ann Otol Rhinol Laryngol 2017;126:61-6. https://doi.org/10.1177/0003489416674962

3 Ruhl DS, Siegal G. Medical malpractice implications of clinical practice guidelines. Otolaryngol Head Neck Surg 2017;157:175-7. https:// doi.org/10.1177/0194599817707943

4 Mathew R, Asimacopoulos E, Walker D, et al. Analysis of clinical negligence claims following tonsillectomy in England 1995 to 2010. Ann Otol Rhinol Laryngol 2012;121:337-40. https://doi. org/10.1177/000348941212100509

5 Windfuhr JP. Faults and failure of tonsil surgery and other standard procedures in otorhinolaryngology. Laryngorhinootologie 2013;92(Suppl 1):S33-72. https://doi.org/10.1055/s-0032-1333253

6 Levine CG, Casiano RR. Revision functional endoscopic sinus surgery. Otolaryngol Clin North Am 2017;50:143-64. https://doi. org/10.1016/j.otc.2016.08.012

7 Youssef A, Ahmed S, Ibrahim AA, et al. Traumatic cerebrospinal fluid leakage following septorhinoplasty. Arch Plast Surg 2018;45:379-83. https://doi.org/10.5999/aps.2017.00913

8 Nyquist GG, Anand VK, Mehra S, et al. Endoscopic endonasal repair of anterior skull base non-traumatic cerebrospinal fluid leaks, meningoceles, and encephaloceles. J Neurosurg 2010;113:961-6. https:// doi.org/10.3171/2009.10.JNS08986

9 Ketcham AS, Han JK. Complications and management of septoplasty. Otolaryngol Clin North Am 2010;43:897-904. https://doi. org/10.1016/j.otc.2010.04.013

10 Thakar A, Lal P, Verma R. Delayed cerebrospinal fluid leak following septoplasty. Ann OtolRhinolLaryngol 2009;118:636-8. https://doi. org/10.1177/000348940911800906

11 Soni RS, Choudhry OJ, Liu JK, et al. Postoperative cerebrospinal fluid leak after septoplasty: a potential complication of occult anterior skull base encephalocele. Allergy Rhinol 2013;4:e41-4. https://doi. org/10.2500/ar.2013.4.0043 
12 Gülșen S, Yilmaz C, Aydin E, et al. Meningoencephalocele formation after nasal septoplasty and management of this complication. Turk Neurosurg 2008;18:281-5.

13 Li M, Mao S, Tang R, et al. Delayed diagnosis and treatment of cerebrospinal fluid leakage in current practice. J Craniofac Surg 2019;30:1657-61. https://doi.org/10.1097/ SCS.0000000000005402

14 Muñoz-Leija MA, Yamamoto-Ramos M, Barrera-Flores FJ, et al. Anatomical variations of the ethmoidal roof: differences between men and women. Eur Arch Otorhinolaryngol 2018;275:1831-6. https://doi. org/10.1007/s00405-018-4992-6

15 Seth R, Haffey T, McBride JM, et al. Intranasal landmarks for adequate L-strut preservation during endoscopic septoplasty. Am J Rhinol Allergy 2014;28:265-8. https://doi.org/10.2500/ajra.2014.28.4042

16 Trinidade A, Philpott CM. Bilateral glossopharyngeal nerve palsy following tonsillectomy: a very rare and difficult complication of a common procedure. J Laryngol Otol 2015;129:392-4. https://doi. org/10.1017/S0022215115000080

17 Sohn DH. Negligence, genuine error, and litigation. Int J Gen Med 2013;6:49-56. https://doi.org/10.2147/IJGM.S24256

18 Hermann R, Lescanne E, Loundon N, et al. French Society of ENT (SFORL) guidelines. Indications for cochlear implantation in adults. Eur Ann Otorhinolaryngol Head Neck Dis 2019;13:193-7. https://doi.org/10.1016/j.anorl.2019.04.006

19 Gualniera P, Mondello C, Scurria S, et al. Experience of an Italian Hospital Claims Management Committee: a tool for extrajudicial litigations resolution. Leg Med 2020;42:101657. https://doi. org/10.1016/j.legalmed.2019.101657

20 Ansarin M. Surgical management of head and neck tumours during the SARS-CoV (Covid-19) pandemic. Acta Otorhinolaryngol Ital 2020;40:87-9. https://doi.org/10.14639/0392-100X-N0783

21 Howard A, McWilliams T, Hannant G, et al. Could no-fault compensation for medical errors improve care and reduce costs? $\mathrm{Br}$ J Hosp Med (Lond) 2019;80:387-90. https://doi.org/10.12968/ hmed.2019.80.7.387

22 Bishop TF, Klotman PE, Vladeck BC, et al. The future of malpractice reform. Am J Med 2010;123:673-4. https://doi.org/10.1016/j. amjmed.2010.03.013

23 Voultsos P, Casini M, Ricci G, et al. A proposal for limited criminal liability in high-accuracy endoscopic sinus surgery. Acta Otorhinolaryngol Ital 2017;37:65-71. https://doi.org/ 10.14639/0392-100X1292

24 di Luca A, Vetrugno G, Pascali VL, et al. Perspectives on patient safety and medical malpractice: a comparison of medical and legal systems in Italy and the United States. J Patient Saf 2019;15:e78-e81. https://doi.org/10.1097/PTS.0000000000000460

25 Coll M, Allegue C, Partemi S, et al. Genetic investigation of sudden unexpected death in epilepsy cohort by panel target resequencing. Int J Legal Med 2016;130:331-9. https://doi.org/10.1007/s00414-0151269-0

26 Partemi S, Vidal MC, Striano P, et al. Genetic and forensic implications in epilepsy and cardiac arrhythmias: a case series. Int J Legal Med 2015;129:495-504. https://doi.org/10.1007/s00414-014-1063-4

27 Tibble HM, Broughton NS, Studdert DM, et al. Why do surgeons receive more complaints than their physician peers? ANZ J Surg 2018;88:269-73. https://doi.org/10.1111/ans.14225

28 Henry LM, Larkin ME, Pike ER. Just compensation: a no-fault proposal for research-related injuries. J Law Biosci 2015;2:645-68. https://doi.org/10.1093/jlb/lsv034 